\title{
Entre el Corte y la Continuidad Hacia una Escritura Crítica
}

La novela de Juan José Saer, El limonero real, que apareció hace poco en Barcelona (Planeta, 1976), parece situarse en el cruce de las dos tentaciones que tironean el relato latinoamericano actual: por un lado, el todavia subsistente atractivo de una "historia" que tiene un interés en sỉ y, por el otro, la escritura pura, donde todo lo que sea "referencia", "reflejo", se diluye hasta la desaparición. No es que El limonero real haga un compromiso, a la manera de un tex to como $L a$ casa verde (Barcelona, Seix Barral, 1966) de Vargas Llosa (en donde un cuento está fragmentado, tratado técnicamente como si fuera un mosaico), y aun como Cien años de soledad (Buenos Aires: Sudamericana, 1967) de Garcia Márquez (en donde prima la historia que, en todo caso, se hace atractiva por la carga de "modos" de contarla que, sin alcanzar a diluirla, la hacen explotar y sugieren un más allá que se centraría en su escritura); yo diría que, si se trata de comparar, el texto firmado por Saer lleva hasta sus últimas instancias lo que está dibujado en los de Onetti en la medida en que lo narrado no es necesariamente un suceso reconocible, un "algo" que un espíritu positivista pueda pesar y medir, sino la narración misma o, lo que es lo mismo, el obsesivo drama de narrar. Para comprender mejor esta idea sobre Onetti, remito al excelente trabajo de Josefina Ludmer ("Contar el cuento", estudio preliminar a J.C. Onetti, Para una tumba sin nombre, Buenos Aires, Sudamericana, 1975), quien llama la atención sobre lo que "marcha" en Para una tumba sin nombre, o sea una densa construcción consciente de sí misma y que va pasando al plano de la historia en una determinación que, de lo contrario, harǐ̀a del relato una empresa lisa, un cuento sin mucha "sociedad", sin mucha denuncia. Saer, repito lleva hasta sus extremos esa tensión que cubre 
el espacio de lo que podrǐamos entender como "la tentativa Onetti".

Me doy cuenta de las dificultades que proponen estas primeras líneas y de los compromisos que implican sobre todo porque, parece, eso que llaman "crítica literaria" debe aclarar las cosas, reducir los problemas que un texto presenta, en suma, tranquilizar a los lectores mediante el sistema de adjetivos al que, parece, están habituados. Aquí, en cambio, la perturbación es inicial. Por de pronto, ¿será cierto que el relato latinoamericano se tiende entre esas dos tentaciones? Además, ¿será cierto, o habrá que demostrarlo, que en Onetti habría un principio de inclusión de ambas direcciones? ¿O todo es una tesis que hace una colega y de la que, a mi vez, extraigo conclusiones que me sirven para empezar a entender a Saer? Y, sobre todo, ¿quién es Saer? Demasiadas preguntas para poder trabajar, para llegar a una zona en la que adelantemos algo y no solamente sigamos pataleando con habilidad en lo que todos sabemos $y$, cuando hablamos de literatura, no podemos olvidar. Por eso, y para no conceder nada, para ser extremista y radical, dirỉa que vamos a entender a Juan José Saer no como "persona-persona" sino como "persona de autor" (expresión que apreciaría Macedonia Fernández), o sea un espacio productivo del que salen textos que, esos sí, tienden una red en la que hay o bien una evolución o bien una permanencia o bien una idea central que hay que, sacándola fuera, perfeccionar. Vamos también a suponer que los lectores tienen su opinión formada sobre Vargas Llosa y que las palabras de más arriba la afectan, supongamos que pensaron-porque se pensó bastante-en el secreto de Cien años de soledad; supondremos que ya no queda gente inerte frente a lo que ocurre en la escritura de Onetti, e incluso, que ya no hay gente inerte frente a lo que ocurre en la escritura de Onetti, e incluso, que ya no hay gente inerte frente a lo que ocurre en la "escritura" o, lo que es lo mismo, que se están modificando los códigos de lectura y que, para leer, no se fija la atención exclusivamente en las tragedias muy dolorosas, por razones psicológicas o sociales, que padecen entidades muy parecidas a nosotros y que se llaman "personajes", con las que simpatizamos o no, que nos envian mensajes muy reconfortantes sobre el comportamiento humano, político, racial, histórico, social, etc.

Sobre estas "aclaraciones/declaraciones" podriamos empezar señalando que ciertos aspectos externos en El limonero real están ya presentes en Cicatrices (1969). Me refiero, principalmente, a lo que puede ser entendido como un "estilo" objetivista, mejor dicho, a lo que puede ser homologado con esa escuela conocida con el nombre 
de "objetivismo" y que ha suscitado las iras de Ernesto Sábato. A esa escuela que, dicho sea de paso, parece haber arraigado mucho más en México que en otros lugares de América Latina (cf. Elizondo, Pacheco, Le-ero, etc.). De este modo, la influencia se disemina y la Argentina entra a competir, pero ya desde hace tiempo, desde Saer mismo en sus relatos anteriores (Unidad de lugar), y aun desde Antonio Dibenedetto (Transfiguración y Angel) y desde Alberto Vanasco (Sin embargo Juan vivia), cuya estirpe objetivista es anterior a la explosión mundial del movimiento y que ha surgido desde determinaciones intransferibles, no imputables a probables "influencias". En principio, para marcar las diferencias habria que recordar que toda descripción es objetivista cuando obedece a sus necesidades de expansión: habría que ver por qué en la Argentina o en México existen necesidades de expandir la descripción en determinado momento de la historia: habria que pensar en una perspectiva gnoseológica que de pronto penetra en la escritura y la modela. En este caso, el problema de las influencias queda resuelto pero, también, se introduce un nuevo factor de molestia: la perspectiva gnoseosociológica que voy a desechar por ahora para retomarla, si logro, en un momento más oportuno de este análisis.

Quedamos, pues, en el aspecto objetivista externo de $E l$ limonero real que también se encuentra en Cicatrices; aquí se describe el juego del baccará como si se tratara de hacer un manual para neófitos; ¿el neófito es el lector? ¿O la descripción es una metáfora de un conocimiento que no interesa, obvio y desechable? Porque puede muy bien suponerse que el lector de Cicatrices es también lector de ruleta y de baccará, puesto que esos juegos forman parte de un elenco de referencias o de conocimientos que incluyen la posibilidad misma, por razones de época, de cultura, de leer un relato latinoamericano, argentino, de Juan José Saer. En El limonero real la extensión descriptiva produce un salto dialéctico pero inesperado: la convicción más corriente desearỉa que desde la mucha descripción se pasara a una cualidad, por ejemplo, el vertiginoso placer, pero aquí hay un corte mucho más vertiginoso, a saber que siempre se está describiendo lo mismo: lo circular es lo que deviene cualidad; lo que pone en evidencia, superficialmente también, otros canales a los que hay que atender: describir siempre lo mismo supone una obsesividad $y$, por el otro lado, rebaja la calidad posible de la acción.

Pero no es que esté contando nada; se cuenta poco, es cierto, y los elementos que integran eso que se cuenta vuelven incesantemente, un poco como en El año pasado en Marienbad, de Alain Resnais; de 
escena que vuelve a escena que vuelve hay simplemente un pivote que ni hace regresar la descripción a fojas cero para corregir la imagen que se pudo haber creado ni acumula rasgos relevantes sobre la imagen que se ha creado y que es, necesariamente, como una estampa. Ese volver y volver que hace pensar en un relato inmóvil es lo que se emparenta con el objetivismo y, muy trivialmente, asegura una clasificación que, de modo insípido, el "público" reconocería.

Digamos no obstante lo que se cuenta; la acción transcurre en las islas cercanas a Santa Fe, sobre el rǐo Paraná; un isleño, en cuya casa hay un árbol que da limones todo el año, trata de llevar a su mujer a una fiesta de fin de año; ella se niega: hace algún tiempo murió su hijo y está de luto; se obstina en no compartir la fiesta de los demás; el hombre va, ayuda a hacer la comida, sus parientes y amigos reclaman a su mujer, la van a invitar pero es en vano; las visitas, la música, la bebida de los preparativos, la fiesta misma, ir hasta el bote, dormir la siesta, defecar, presenciar un coito, dormir, hacer el fuego, recordar lo que ya ha sido dicho, pensar en lo que se recuerda, ir, volver. Eso es todo; cada instancia retorna, no hay final, no hay corte salvo que las instancias mismas están cortadas en su raĭz porque indican su irremediable carácter de fragmento, lo que no se integra en una línea contínua pero impone, al mismo tiempo, el secreto de su integración en otro nivel, en un plano que la lectura recoge y que la crítica debería poder extrapolar para comprender ya no la historia que se cuenta sino lo que ocurre, lo que está ocurriendo al contarla. Creo que se ve, entonces, de qué se trata. Se ve, entonces, el camino que vamos a seguir.

Ante todo la narración se hace con palabras y estas palabras, por su disposición en frases, configuran imágenes que nosotros percibimos y cuyo sentido es que vuelven constantemente; es obvio que las palabras vuelvan, simplemente porque no es su aparición puntual y única la condición de un cambio de imágenes, no lo es que las imágenes retornen, pero cuál es la significatividad de tal retorno: justamente algo que está entre las palabras y las imágenes, algo que las palabras pueden otorgar, a saber la imposibilidad de vaciarlas aunque se las repita o se las reemplace o, en fin, se realice con ellas toda suerte de operaciones; es decir, un infinito que necesita de un espacio para hacerse presente y ese espacio le es proporcionado por las palabras que no cesan, que actúan. Ya estamos, por lo tanto, en otra cosa: repetir es abrirle camino a un infinito que las palabras transportan a través de lo que en ellas es inagotable, la significación. Dicho de otro modo, el significante es infinito, en las palabras que lo ejecutan 
se da ese torbellino y lo que la escritura trata de hacer es orientarlo, buscarle la vuelta, hacer que sea esa dimensión que un exceso de confianza en la representación y el reflejo refrenan; en la postura del reflejo la palabra es mero vehículo, historia congelada, no es una viva producción que viene desde el origen de los signos y es todavía objeto de trabajo. Estamos, pues, en una zona quemante: la repetición de la imagen nos conduce a la duración del significante; es ahí donde nos debemos situar.

Pero el significante es todo lo que está en las palabras y más allá de ellas $y$, por eso mismo, podría ser nada: su fuerza no consiste, entonces, en su presencia sino en su presencia de cierta manera, articulada de cierta manera; el significante no deja de ser infinito porque haya logrado una "forma" y es la forma lo que surge, a su vez, de lo que las palabras arreglan, componen, de lo que les confiere un trabajo que se hace con ellas al arreglarlas. Por lo tanto, y ante todo, hay una estructuración que no se agota en la estructura; la estructura es, de alguna manera, una metáfora de la estructuración, o sea de la energía que ha intervenido para conseguir una "forma" que encerrando la infinitud del significante no hace sino presentarlo en esta cualidad.

¿Cómo es aquî? ¿Cómo acercarse a la "forma" sin apelar a la idea, por ejemplo, de "novela", o de una historia completa, o de "estilo"? Para acercarse hay que elegir en función de un esquema anterior al texto en cuestión pero que no lo ignore. Elegir, por ejemplo, un núcleo de la acción y un elemento verbal: el núcleo que me parece pertinente (porque, fragmento ejemplar, condensa lo que en un comienzo puede entenderse como "causa" de acciones posteriores) es el siguiente: "Una mujer no quiere ir a una fiesta; en el patio de su casa hay un limonero real"; el elemento-sintagmaverbal es: "Amanece/y ya está con los ojos abiertos".

Ese primer núcleo establece dos continuidades, la de una negativa (la de la mujer) y la de una presencia sin ciclos (pues el limonero real da limones todo el año). La negativa de la mujer no tiene fisuras y genera actos sucesivos: irse, pensar en ella, incitar a otros a buscarla, respetar sus razones, no respetarlas. De cierta manera, la negativa de la mujer es un elemento permanente e inmóvil frente a la movilidad de los otros; como inmóvil sugiere un misterio que se trata de dilucidar no por razonamientos sino volviendo en las descripciones, reiterando, insistiendo. Más que asegurar la continuidad de la historia, "la mujer que no quiere ir a la fiesta" asegura la continuidad del relato y determina su estructura; el limonero juega 
un papel parecido pero en la afirmación: el misterio de su fecundidad, otro nudo al que si bien no se vuelve en función de una argumentación, está tan firme en su puesto como la estructura misma. Entonces: estas continuidades son una manera de realizar una estructura que la insistencia muestra mediante fragmentos, estructura que es la forma misma, el campo de la operación del significante. Demás está decir que el elemento verbal, "Amanece/y ya está con los ojos abiertos", ante todo abre el tex to y lo cierra y reaparece puntuando el relato o sea otorgándole un ritmo que, en lǐneas generales, podríamos homologar a un sostenuto interrumpido: una escena se prolonga $y$, cuando aparece este sintagma, se corta, se inicia otra, luego otra vez el corte por medio del mismo sintagma y asî hasta el final, en donde lo único que queda como afirmación, como conclusión cuyas consecuencias habria que sacar, es ese sintagma que supone una preeminencia simultánea de dos fuerzas implicadas en las funciones que cumple: contar y reanudar; según estas últimas el recomenzar está marcado por el sintagma verbal, y es el recomenzar de un retorno-que podría no concluir-al mismo asunto: si, por lo tanto, cado modo del mismo asunto, limitado por el sintagma verbal (que por límite hace de muralla circular pero espiralada porque el mismo asunto se achica, se aprieta, se condensa) tiene aspecto fragmentario, el sintagma verbal, por el contrario restituye un flujo que por un lado tiene que ver con la continuidad asegurada por los dos vertientes de la escena primera (la mujer que no quiere ircontinuidad por la negación-/el limonero real-continuidad por la afirmación), en tanto la escena primera genera como por impulsos la narración y, por el otro, con lo único que no se corta, a saber con el trabajo de articular eso que llamamos "escritura" y que se cumple incesantemente entre el corte y la continuidad. Pero, además, como sintagma verbal constituye un punto de condensación bien preciso, condensación de las energìas escriturarias, esencialmente transformadoras; el sintagma verbal es como un recinto en el que tienen lugar operaciones $y$, por eso, propone un simil del relato entero, que no se concibe sino en una acumulación orgánica de transformaciones.

La escena primera, "una mujer no quiere ir a una fiesta", es un motor de la narración porque motiva o desencadena acciones que, en definitiva, configuran la masa del relato. Pero, además, es un núcleo que actúa o genera, como se quiera, en otro nivel si consideramos esta frase en el cruce entre la locución directa y la indirecta. La primera sería la que emana de personajes que se manifiestan como tales mediante diálogos; la segunda, la que el narrador o personajes ter- 
ceros atribuyen a personajes primeros (los segundos son los que están en toda interlocución, ya sea con los primeros, ya con los terceros, son el "tú" necesario a todo discurso de un "yo", ya sea que aparezca hablando de sí mismo o manifestándose por sí mismo, ya sea que se haga cargo de palabras de otros). En este cruce, pues, la "mujer" dice que "no" solo en una oportunidad, en el fragmento inicial caracterizado por la afirmación en todo lo que sea descripción de actos de personajes ("le alcanza el mate"/"Ella sigue hilvanando ...." $/$ "...y después arranca con los dientes..."/ "Wenceslao pasa despacio..." "le devuelve el mate ...") y por una generalización del "no" en todo lo que sea locución directa ("No puedo andar cosiéndolas. .." / "No querés venir conmigo...? / "Hoy no" / "No vas a saludar a tu hermana. . .?" / "No, hoy no" / "El año pasado tampoco fuiste" / "No tengo nada con ella" / "¿... sin salir a ninguna parte?" / "Para mi no" / "Ellos saben que yo no salgo"); es notable que cuando el fragmento inicial se completa mediante un flash-bak arcaico en el que aparecen padre e hijo (que en el presente recibe toda la carga de los "no" de la mujer) hay un diálogo claramente afirmativo ("Llegamos-dice Wenceslao./"Parece que sĩ-dice el padre".) De todos modos lo importante es que después de ese "no" directo, posteriormente su "no" siempre viene indirectamente, o sea que se dice que dice que no ("- ¿Y ella? -dice"./"--No, ella no viene-dice Wenceslao"). Tenemos aquǐ un nuevo esquema que completa el anterior: preguntas indirectas engendran respuestas que se hacen cargo, indirectamente, de una negación inicialmente vertida en forma directa; es este esquema el que reaparece siempre igual, como pregunta siempre alusiva y respuesta siempre haciéndose cargo de la primera negación, encarrilada, como si la alusión no puediera ser otra cosa, por ejemplo "está bien" o "está mal" o "está enferma". Vemos, por lo tanto, hasta qué punto relatar, en este texto, es hacerse cargo de la escena inicial, cómo se trata de un embrión que no es sólo de una anécdota sino de todo lo que transcurre delicadamente por debajo y transporta criterios más matizados de la escritura.

Pero, además, hay otra cosa: el "no" de la mujer directo e inicial, anticipa no sólo sus propios "no" indirectos posteriores sino también el hecho de que no puede responder-y en efecto no responde-puesto que no le hablan; es atribuilda tanto en la pregunta como en la respuesta, no es presentada: en esa atribución está su ausencia de la que el "no" inicial viene a ser el anticipo, lo que hace suponer, en cuanto el "no" marca el relato, que el relato bebe su 
fuerza de la negación; por otra parte, esto pone también en evidencia que el circuito "pregunta y respuesta"- que parece caracterizar el desarrollo del embrión inicial-es del relato y no de la representación ya que, para aclarar, no hay una modificación de la idea, lo que no impide no obstante que se siga insistiendo, o sea escribiendo. De este modo, como todo gira en torno a ese movimiento de negación (que, recordémoslo, no era antagónico de la continuidad, ya sea del limonero, ya del sintagma verbal), las cosas ocurren como si en realidad la pregunta fuera aparente, necesaria tan sólo para ser repetida y hubiera una verdad que está no en la respuesta sino en la "norespuesta", en la medida en que la "no respuesta", la ausencia, lo inmodificable constituye lo que se está contando. En consecuencia, se trata de un hablar falso y de un callar verdadero que, para seguir afirmando lo único afirmable, lo que se ve, viene a ser el de la escritura misma que hace predominar lo que hay en ella de sistema de inscripciones y que no emplea la representación como criterio de verdad porque su criterio de verdad está en su materia misma.

De este modo, ya tenemos algo así como un punto de partida para entender no quizás la "forma" que tiene este tex to sino los movimientos que tienden a constituir la "forma"; lo que queda es, creo, que para llegar a una forma es preciso que ciertas tensiones se resuelvan en escritura: reconocerlas es ya entrar en el nudo de la cuestión. Pues bien, esa tendencia a la "forma", por lo ya dicho, podría estar regida por un rasgo que inicialmente presenté como externo pero que ahora se nos muestra como inherente a la estructura: está en la red que trazan esos movimientos constituyentes, mejor dicho se inscribe en esa red, cobra relieve en ella: es la insistencia, justamente el rasgo que nos hacía ver este tex to como "objectivista".

En este instante en que una frase de Lacan, sacada de su análisis de La carta robada (Escritos II, México, Siglo XXI, 1975), viene a echar un haz de luz sobre el equǐvoco, diré algo sobre el equívoco: la insistencia, relacionada con el objetivismo, me hizo pensar en un momento en la obsesividad que caracteriza a esa escuela: volver y volver, redondear y redondear, manía de la descripción que para mejor no avanzar se sitúa en un tiempo presente predilecto de las novelas objetivistas, que se pliega, de este modo, a una pulsión obsesiva que puede ser caracterizada como paranoica: búsqueda lúcida, inmóvil, de un matiz que lo explicarỉa todo pero que por lo mismo que nunca aparece, crea una enorme enfermiza sospecha. Objetivismo como paranoia en el texto pero en la medida en que reduce el texto a ese esquema-ignorando que toda descripción, asĩ no sea recurrente y 
actual, es obsesiva y persecutoria-, resulta paranoia en el enfoque, no sólo por la reducción sino por la inmovilización que de ella resulta pues no se puede ir más allá, la serie "insistencia-obsesividadobjetivismo-paranoia" es final y termina por parecerse a un adjetivo, no al esbozo de una significación. Es para liquidar este equívoco que viene la frase de Lacan: "un automatismo de repetición que tomaria su principio en la insistencia de la cadena significante".

De este modo las cosas cambian radicalmente; ya no se trata de paranoia, en El limonero real al menos, como texto presuntamente objetivista, sino de un obsesivo "no" progresar de la acción, de lo cual la primera consecuencia es una suspensión de los efectos de una acción que desde cierta ideología del relato debe necesariamente desarrollarse y seducir con su variación-que descansa sobre la repetición, ahora vista como no controlada, y se confunde con la insistencia misma, que sería, lacanianamente, un modo de actuar de la cadena significante o sea de la cadena material.

Dicho de otro modo, y para incluir lo que está entre los guiones, obsesión, suspensión, repetición, son como niveles de la insistencia, fuerza del significante, manifestación del significante en tanto, insatisfecho, se reproduce sin cesar en la narración que reabsorbe sus propios hilos-sus modos-y vuelve a hacerlos emerger. Hay, entonces, una reproducción pero no de un algo externo al significante-materia textual-sino de la insistencia misma, o sea de lo que, parece, de más cuenta de su carácter incesante. Si hay obsesión, por lo tanto, no tiene por qué ser vista en los personajes ni en el narrador sino bien localizadamente en la narración que aparece como un campo fuertemente movilizado y no ya como un producto final en el que nada se mueve porque lo que se movió lo hizo fuera de él.

Pero la narración es de un narrador que, al hacerse vehículo de la insistencia, se fragmenta, pulveriza sus aceptadas funciones de conocedor, desaparece en la insistencia que prima. $Y$ eso se manifiesta no sólo en las escenas que vuelven a ser contadas sino en las oscilaciones de los tiempos verbales: de pronto, el narrador emplea el pretérito ("dijo": tiempo de lo conocido que se transcribe), de pronto el presente ("dice": tiempo de lo apenas observado), de pronto el futuro ("remará": tiempo de la conjetura, esencialmente subjetivo si es que el narrador expresa un punto de vista sobre lo que narra). Y, mediante estos tres tiempos, articulados para narrar similares escenas, el relato toma forma como relato de un relatar, como relato del trabajo de relatar. Pero todas estas maneras de frag- 
mentar el punto de vista-que guardan una estricta correspondencia con los fragmentos en que se constituye la historia no resultan de una exterior actitud de vanguardista, de técnico: creo ver detrás de ellas esta fuerza de la insistencia capaz de trazar un hilo interno por dentro de la fragmentación hasta redondear una historia, como historia que, siendo incapaz de desarrollarse, es incompleta pero que, por aceptar su incompletud, brinda una nueva unidad, un nuevo tipo de unidad. ¿Dónde se establece? Precisamente en la exhibición de todos estos términos, más bien en la administración de todos estos planos que, en definitiva, producen la "forma" de este texto, este texto mismo. $\mathrm{Y}$ ello supone actualizar un poder superior cuyo sentido no es un completamiento de sentido sino una presencia organizada de sí mismo, lo que antes designábamos como el "significante".

¿Tiene algo de ideológica esta conclusión? Ciertamente, en un doble sentido. Ante todo, porque como trámite analítico surge de una toma de partido frente a otras posibilidades de "ver" en un texto; complementariamente, ésta toma de partido se hace cargo de fuerzas, de pulsiones, de una materialidad-el significante-que seria lo que hay que ver en un texto y hacer salir de él para entender de qué manera un texto-como objeto específico (frente a otros)-y singular (respecto de los que se definen por su misma especifidad)puede proponer zonas de contacto con lo que alienta en otras producciones humanas, en otras-en todas-las producciones de lo real. En segundo lugar, porque de parte del texto y de parte del análisis que hacemos de él, situarse en este campo supone denunciar el pacto que mantiene, a través de la ideología, la ideología que cierra las posibilidades sociales de una lectura de las fuerzas y no de las exterioridades. ¿Cuáles son los módulos de dicha ideologìa literaria? Más bien es un conjunto de "ideologias" que aquí se trata de desbaratar en su dominio desde diversas acciones críticas; ideología de un contar seguido y orgánico, desde la fragmentación; ideologia de un narrador como el que otorga la unidad, desde el relevamiento del trabajo de narrar; ideologia de la paranoia como atractivo y ambiguo desestructurante (la enfermedad como problemática de la desviación y la norma), desde una acción anterior de la insistencia como energía del significante. El texto, entonces, según lo podemos ver desde las condiciones del "ver" que asumimos, ataca esas ideologías, las desmonta, las critica ferozmente pero sin proclamarlo, como si se tratara de poca cosa, como si fuera posible, y aun fácil, una lectura que permitiera entrar en ese campo tan contradictorio y deslindar lo que allǐ está ocurriendo. 
Texto generoso, por lo tanto, carnoso y persuasivo porque supone capacidades allì donde realmente están, retenidas y reprimidas, texto que da allï donde debe darse y que es el preciso lugar en el que la norma exige que poco se dé, lugar de una lectura pobre y sometida. Es esta generosidad un acto de arrojo porque para que su donación sea aceptada, para que la lectura proporcione el verdadero placer que reside en sus articulaciones (no sólo de éste sino de todos los textos), en su verdad, el espacio en el que se cumple-la sociedad-debe sufrir un cambio. Entretanto, el placer que proporciona la lectura es contradictorio pues lo principal de su fuente está en la oposición, en la ruptura, en que hace aflorar lo que por lo general permanece quieto y oscuro, asfixiado, reducido a la insignificancia, en otras palabras la muerte.

Una última consideración, otro equívoco: el de las categorias que se emplean para analizar un tex to latinoamericano. Algunos se van a indignar porque le atribuimos un significante, porque suponemos que ese significante arraiga en el inconsciente: como si los latinoamericanos carecieran de él; algunos no van a entender que no se lo califique: si vale la pena o no, de acuerdo con el juicio de que escribe, que los demás gasten su tiempo en verificar: como si importara lo que el crítico valora más que lo que el crítico "hace"; algunos van a fruncir el ceño frente a la ubicación del concepto de ideología; extrañarán que no se condene al texto en función de su complejidad, como si la capacidad de emitir una condena supusiera un certificado de pureza ideológica, como si la ideología no fuera todo un sistema que se muestra en sus operaciones y que hay que reconocer, como si se tratara de sacarse el lazo de en cima "declarando": claridad=ideologia progresista, complejidad=ideología reaccionaria; algunos van a gritar, categorías extranjeras, Lacan, como si las categorías nacionales fueran superiores, como si aprovechar de todo lo que pueda ayudar a pensar no significara meramente constituir categorìas que, si sirven, se validan $\mathrm{y}$, si no, por más nacionales que sean, llevan a la parálisis y a lo que se designa como dependencia pues desarma, obliga no ya a aceptar a Lacan sino a la televisión en color, y al fascismo que, por no se sabe qué rara transformación, es aceptado como más criollo que el comunismo. Disipemos el equîvoco: estamos frente a un trabajo para hacer un trabajo; reconocerlo instaura una alegrìa que se aleja de la tristeza dependiente y dignifica la lectura. 
